\title{
Investigation of the association of G-7A and T-138C single nucleotide polymorphisms on the promoter of MGP gene with renal stone
}

\author{
Mohammad Keramatipour ${ }^{1}$, Babak Ahadi ${ }^{2}$, Mohsen Taghizadeh ${ }^{1}$, Ali Tabibi ${ }^{\star}{ }^{\star}$, Farshad Zohrabi ${ }^{2}$, Babak Javanmard ${ }^{1}$, \\ Behzad Narouie $^{2} \mathbb{D}$
}

${ }^{1}$ Department of Medical Genetics, Tehran University of Medical Sciences, Tehran, Iran

${ }^{2}$ Urology and Nephrology Research Center; Department of Urology and Renal Transplantation, Shahid Labbafinejad Medical Center, Shahid Beheshti University of Medical Sciences, Tehran, Iran

\section{A R T I C L E I N F O}

Article Type:

Original

\section{Article History:}

Received: 17 February 2018

Accepted: 2 June 2018

ePublished: 10 July 2018

\section{Keywords:}

Renal stone

Single nucleotide polymorphisms Kidney

\begin{abstract}
A B S T R A C T
Introduction: Renal stones, due to their heavy costs of diagnosis and treatment, have a considerable financial burden on health system. Family history and genetic susceptibility are important factors in stone formation. Matrix Gla-protein (MGP) is a gene that has a known role in inhibition of arterial calcification. It is thought that MGP may be involved in pathogenesis of calcium nephrolithiasis as an ectopic calcification.

Objectives: This study aims to demonstrate association of G-7A and T-138C single nucleotide polymorphisms (SNPs) of this gene with kidney calcium stone in Iranian population. Patients and Methods: Seventy-nine patients with renal stone who underwent PCNL or open surgery were enrolled. Blood samples from each patient and his/her parents were taken and DNA extraction was done using salting out and phenol-chloroform extraction protocols. Genotypes for the MGP T-138C and G-7A polymorphism were determined by PCR-sequencing methods. Statistical analysis and transmission disequilibrium test were done by SPSS software. Results: Total of 235 DNAs were extracted. The most frequent nucleotide is G (67\%) in G-7A SNP and T (69\%) in T-138C SNP. The CA haplotype was not seen in observed population and other haplotypes had same frequencies. No over transmission of alleles in two SNPs and no association of MGP Polymorphisms and nephrolithiasis were observed.

Conclusion: This study is the first family based investigation in Iranian population, which shows, no specific pattern of transmission and no effect of inherited SNPs on stone formation.
\end{abstract}

Implication for health policy/practice/research/medical education:

This study is the first family based investigation which was done in patients with kidney calcium stone, demonstrate association of G-7A and T-138C single nucleotide polymorphisms (SNPs) of this gene in Iranian population. This study showed higher frequencies of $\mathrm{G}$ and $\mathrm{T}$ alleles in -7 and -138 SNPs of MGP gene, respectively. However, no specific pattern of transmission was seen and inherited SNPs have no effect on stone formation.

Please cite this paper as: Keramatipour M, Ahadi B, Taghizadeh M, Tabibi A, Zohrabi F, Javanmard B, et al. Investigation of the association of G-7A and T-138C single nucleotide polymorphisms on the promoter of MGP gene with renal stone. J Nephropharmacol. 2018;7(2):145-148.

\section{Introduction}

Renal stone is the third most common disorder of urinary tract and has a high rate of recurrence (1). Renal Stones typically cause considerable pain and suffering. In addition, diagnosis and treatment of this disease result in a substantial financial burden (2). Family history play an important role in kidney stone formation (3). This indicates the involvement of genetic factors in stone formation. Detection of underlying genetic susceptibility can help to identify individuals who are at the risk of stone formation.

Most kidney stones contain calcium (4,5) and hypercalciuria is an important risk factor for nephrolithiasis (6). Because maintenance of the calcium balance is complicated and many organs are involved in calcium homeostasis, it seems that hypercalciuria is a complex trait and has polygenic etiology (7). Several studies were done to identify genes associated with hypercalciuria (6-8). 
Matrix Gla-protein (MGP) is an approximately $14 \mathrm{kD}$ protein, which has an important role in inhibition of arterial calcification. The human MGP gene is located on chromosome 12, consists of four exons and three large introns $(9,10)$. The pathogenesis of kidney stone formation, as an ectopic calcification, and vascular calcification is similar; and MGP was found to be highly expressed in the renal tubular epithelial cells which increased the risk of kidney stone formation (11-13). Single nucleotide polymorphisms (SNPs) in the coding region of genes are likely to affect their function and alter the quality or quantity of translated protein productions (14). Several SNPs in MGP gene were identified and correlations of them with kidney stone were studied $(13,14)$. Among these SNPs, G-7A and T-138C polymorphisms seem to be more important $(15,16)$. This paper is the first family based study which demonstrates association of G-7A and T-138C SNPs with kidney calcium stone in Iranian population.

\section{Material and Method \\ Patient selection}

Renal stone forming patients underwent PCNL or open surgery between November 2008 and March 2010 at the Labafinejad hospital, Tehran, Iran, were selected. To be included in the study, patients should have at least one calcium oxalate stone and alive and accessible parents. Patients with history of other known familial disease, history of taking long-term medications or known obstruction in urinary system were excluded. Each patient and his/her parents were studied as a triose. All patients were informed about the study and satisfaction form was filled by them.

\section{DNA extraction}

Blood samples were taken at the Labafinejad hospital and transported to the laboratory where DNA extraction was performed using salting out and phenol-chloroform extraction protocols. Extracted DNA was quantified spectrophotometrically by NanoDrop (Thermo Fisher Scientific, Wilmington, USA).

\section{PCR amplification}

PCR was performed in a $35 \mathrm{ml}$ reaction volume containing $0.3 \mathrm{M}$ of each sense and antisense primer, as below:

- Sense primer:

5'-AAGCATACGATGGCCAAAACTTCTGCA-3'

- Antisense primer:

\section{5'-GAACTAGCATTGGAACTTTTCCCAACC-3'}

The amplification reaction was done using $0.2 \mathrm{mM}$ of dNTP, 10X PCR buffer,

$2.5 \mathrm{mM} \mathrm{MgCl} 2$, and $3 \mathrm{U}$ Taq DNA polymerase. The running conditions were predenaturated at $94^{\circ} \mathrm{C}$ for 5 minutes, followed by 35 cycles of denaturation at $94^{\circ} \mathrm{C}$ for 30 seconds, annealing at $60^{\circ} \mathrm{C}$ for 30 seconds, and synthesis at $72^{\circ} \mathrm{C}$ for 1 minute. Final extension was conducted at $72^{\circ} \mathrm{C}$ for 5 minutes.

\section{Genotyping}

Genotypes for the MGP T-138C and G-7A polymorphism were determined by PCR-sequencing methods.

\section{Ethical issues}

The research followed the tenets of the Declaration of Helsinki. Informed consents were obtained. All patients took part in this study voluntary. The research was approved by ethical committee of Urology and Nephrology Research Center, Shahid Beheshti University of Medical Sciences. This study was extracted from residential thesis of Babak Ahadi (\# 90-126).

\section{Statistical analysis}

The transmission pattern of alleles from parents to the child was compared by the Transmission disequilibrium test (TDT). Relative risk was estimated by the calculation of the odds ratio (OR) with $95 \%$ confidence interval. SPSS software was used for analyzing demographic data and $\mathrm{R}$ software for TDT estimation.

\section{Results}

Total of 235 DNAs were extracted from 79 patients' and their parents' blood samples. (Two patients were siblings). Fifty-two patients $(65.82 \%)$ were male and 27 patients (34.18\%) were female. There are two forms of nucleotides (A and $G$ ) in -7 SNP so 3 different genotypes are probable in this SNP (AA, AG and GG), also there is C or T in -128 SNP and the probable genotypes would be CC, CT and TT. The most frequent nucleotide is G in G-7A SNP and T in T-138C SNP (Table 1).

Heterozygous genotypes (AG and $\mathrm{CT}$ ) are the most frequent genotypes in both SNPs (Table 2).

Table 3 demonstrates the frequencies of genotypes

Table 1. Frequencies of observed SNPs

\begin{tabular}{llcl}
\hline & & Number & $\%$ \\
\hline \multirow{2}{*}{ SNP-7 } & G & 317 & 67 \\
& A & 153 & 33 \\
\multirow{2}{*}{ SNP-138 } & T & 323 & 69 \\
& C & 147 & 31 \\
\hline
\end{tabular}

Table 2. Frequencies of genotypes in observed SNPs

\begin{tabular}{llcl}
\hline & & Number & $\%$ \\
\hline \multirow{4}{*}{ SNP -7 } & GG & 105 & 45 \\
& AG & 101 & 43 \\
& AA & 29 & 12 \\
\multirow{5}{*}{ SNP-138 } & TT & 117 & 50 \\
& CT & 92 & 39 \\
& CC & 26 & 11 \\
\hline
\end{tabular}


according to patient, father and mother.

Considering two SNPs for each person, on the other hand, there would be four haplotypes including CA, CG, TA and TG. In observed population the CA haplotype does not exist and the frequencies of other haplotypes were almost the same (Table 4).

Tables 5 and 6 show the results of transmission disequilibrium Test (TDT) which was done to evaluate the effect of inherited SNPs on stone formation.

\section{Discussion}

The role of MGP in inhibition of calcification in arteries is well illustrated, and its increasing expression in the kidneys of the stone-forming rats suggested possible involvement of this protein in renal calcification (12). In

Table 3. Frequencies of genotypes in patients and parents

\begin{tabular}{cccccc}
\hline \multirow{5}{*}{ SNP-138 } & & Patient & Father & Mother & Total \\
\hline \multirow{5}{*}{ SNP -7 } & TT & 43 & 30 & 44 & 117 \\
& CC & 9 & 8 & 9 & 26 \\
& CT & 27 & 40 & 25 & 92 \\
& Total & 79 & 78 & 78 & 235 \\
& GG & 34 & 37 & 34 & 105 \\
& AA & 10 & 6 & 13 & 29 \\
& AG & 35 & 35 & 31 & 101 \\
& Total & 79 & 78 & 78 & 235 \\
\hline
\end{tabular}

Table 4. Frequencies of possible haplotypes

\begin{tabular}{lcc}
\hline & Number & $\%$ \\
\hline TA & 170 & 36 \\
TG & 153 & 33 \\
CA & 0 & 0 \\
CG & 147 & 31 \\
\hline
\end{tabular}

Table 5. Frequencies of parent's transmitted and non-transmitted alleles in SNP-7

\begin{tabular}{lccc}
\hline \multirow{2}{*}{ Transmitted Allele } & \multicolumn{3}{c}{ Non-Transmitted Allele } \\
\cline { 2 - 4 } & G & A & Total \\
\hline G & 71 & 33 & 104 \\
A & 37 & 19 & 56 \\
Total & 109 & 52 & 160 \\
\hline
\end{tabular}

TDT $=0.23, P=0.63$

Table 6. Frequencies of parent's transmitted and non-transmitted alleles in SNP-138

\begin{tabular}{lccc}
\hline \multirow{2}{*}{ Transmitted Allele } & \multicolumn{3}{c}{ Non-Transmitted Allele } \\
\cline { 2 - 4 } & $\mathbf{T}$ & $\mathbf{C}$ & Total \\
\hline $\mathrm{T}$ & 74 & 38 & 112 \\
$\mathrm{C}$ & 30 & 17 & 47 \\
Total & 104 & 55 & 159 \\
\hline
\end{tabular}

the present study, we tried to investigate the association of 2 SNPs of this protein and stone formation in a family based study in Iranian population. However, our results indicated no significant association between the MGP polymorphism and nephrolithiasis. Also, analysis of data showed no over transmission of alleles in two SNPs (transmission disequilibrium test, -138 SNP TDT value $\approx$ $1.32,-7$ SNP TDT value $\approx 0.37$ ).

As an important factor in arterial calcification, polymorphisms of the MGP gene were studied in vascular calcification, and myocardial infarction. Herrmann et al identified eight polymorphisms in the coding and 59-flanking sequences of the MGP gene; among them A-7 polymorphism was associated with an increased risk of plaque calcification and MI (16). Although, in vitro analysis of MGP promoter activity revealed that the C-138 allele reduced promoter activity in cells but this polymorphisms has no significant impact on artery calcification $(16,17)$.

Lu et al identified 18 polymorphisms of MGP gene in Chinese Han population and they find an association between SNPrs4236 and kidney stones in this population (13). There is a similar study in Japanese population which indicates the role of MGP and its polymorphisms in renal stone formation (14).

In Iran, Abiri et al studied T-138C and A-7G polymorphisms in the MGP gene in patients with coronary artery disease (18). The findings of our study, which show a higher frequency for G allele in -7 SNP in investigated population is consistent with the findings of Abiri et al study. However, the result in -138 SNP in our study show a higher frequency of $\mathrm{T}$ allele and in Abiri et al investigation show a dominancy of $\mathrm{C}$ allele. This is notable that in Abiri et al study the frequency of $\mathrm{T}$ allele in case group is insignificantly higher than $\mathrm{C}$ allele, which is now consistent with our findings and may indicate a role of $\mathrm{T}$ allele in calcification whether in arteries or in kidney.

Our result also showed no over transmission of alleles in two SNPs. This may be because of the sample size, therefore, higher sample size may be required to establish the role of transmission of alleles in kidney stone. On the other hand, to our knowledge, there is no other study to investigate the transmission of these alleles in Iranian population; more research on this topic needs to be undertaken before the association between SNPs and transmission of alleles is clearly understood.

\section{Conclusion}

This study is the first family based investigation which was done in patients with kidney calcium stone in Iranian population and showed higher frequencies of $G$ and $T$ alleles in -7 and -138 SNPs of MGP gene, respectively. However, no specific pattern of transmission was seen and inherited SNPs have no effect on stone formation. Future studies with a higher sample size and considering 
comparison between case and control group are recommended.

\section{Acknowledgments}

Authors would like to acknowledge our colleagues in Labbafinejad hospital operation room, Shahid Beheshti University of Medical Sciences and Department of Medical Genetics, Tehran University of Medical Sciences for their leading suggestions on this manuscript.

\section{Authors' contribution}

At conceived the study and contributed reagents and tools. BA, MT and MK performed the experiments. FZ, $\mathrm{BN}$ analyzed the data and drafted the final manuscript; all authors read, revised, and approved the final manuscript.

\section{Conflicts of interest}

There were no points of conflicts.

\section{Ethical considerations}

Ethical issues (including plagiarism, misconduct, data fabrication, falsification, double publication or submission, redundancy) have been completely observed by the author.

\section{Funding/Support}

This project funded by Urology and Nephrology Research Center, Shahid Beheshti University of Medical Sciences and extract from Dr. Babak Ahadi residential thesis with number 90-126.

\section{References}

1. Coe FL, Keck J, Norton ER. The natural history of calcium urolithiasis. JAMA 1977;238:1519-23.

2. Stamatelou KK, Francis ME, Jones CA, Nyberg LM, Curhan GC. Time trends in reported prevalence of kidney stones in the United States: 1976-1994. Kidney Int 2003;63:1817-23.

3. Curhan GC, Willett WC, Rimm EB, Stampfer MJ. Family history and risk of kidney stones. J Am Soc Nephrol 1997; 8:1568-73.

4. Jawalekar S, Surve VT, Bhutey AK. The composition and quantitative analysis of urinary calculi in patients with renal calculi. Nepal Med Coll J 2010;12:145-8.

5. Pak CY, Poindexter JR, Adams-Huet B, Pearle MS. Predictive value of kidney stone composition in the detection of metabolic abnormalities. Am J Med 2003;115:26-32.

6. Moe OW, Bonny O. Genetic hypercalciuria. J Am Soc Nephrol 2005;16:729-45.
7. Renkema KY, Lee K, Topala CN, Goossens M, Houillier P, Bindels RJ, et al. TRPV5 gene polymorphisms in renal hypercalciuria. Nephrology Dialysis Transplantation 2009; 24:1919-24.

8. Scott P, Ouimet D, Proulx Y, Trouvé ML, Guay G, Gagnon B, et al. The 1 alpha-hydroxylase locus is not linked to calcium stone formation or calciuric phenotypes in French-Canadian families. J Am Soc Nephrol 1998;9:425-32.

9. Schurgers LJ, Cranenburg EC, Vermeer C. Matrix Glaprotein: the calcification inhibitor in need of vitamin $\mathrm{K}$. Thromb Haemost 2008;100:593-603.

10. Cancela L, Hsieh CL, Francke U, Price PA. Molecular structure, chromosome assignment, and promoter organization of the human matrix Gla protein gene. J Biol Chem 1990;265:15040-8.

11. Fraser JD, Price PA. Lung, heart, and kidney express high levels of mRNA for the vitamin K-dependent matrix Gla protein. Implications for the possible functions of matrix Gla protein and for the tissue distribution of the gamma-carboxylase. J Biol Chem 1988;263:11033-6.

12. Yasui T, Fujita K, Sasaki S, Sato M, Sugimoto M, Hirota $\mathrm{S}$, et al. Expression of bone matrix proteins in urolithiasis model rats. Urol Res 1999; 27:255-61.

13. Lu X, Gao B, Liu Z, Tian X, Mao X, Emmanuel N, et al. A polymorphism of matrix Gla protein gene is associated with kidney stone in the Chinese Han population. Gene. 2012;511:127-30.

14. Gao B, Yasui T, Itoh Y, Tozawa K, Hayashi Y, Kohri K. A polymorphism of matrix Gla protein gene is associated with kidney stones. J Urol. 2007;177:2361-5.

15. Farzaneh-Far A, Davies JD, Braam LA, Spronk HM, Proudfoot D, Chan SW, et al. A Polymorphism of the Human Matrix $\gamma$-Carboxyglutamic Acid Protein Promoter Alters Binding of an Activating Protein-1 Complex and Is Associated with Altered Transcription and Serum Levels. J Biol Chem. 2001;276:32466-73.

16. Herrmann SM, Whatling C, Brand E, Nicaud V, Gariepy J, Simon A, et al. Polymorphisms of the Human Matrix Gla Protein (MGP) Gene, Vascular Calcification, and Myocardial Infarction. Arteriosclerosis, Thrombosis, and Vascular Biology. 2000;20:2386-93.

17. Kobayashi N, Kitazawa R, Maeda S, Schurgers LJ, Kitazawa S. T-138C polymorphism of matrix gla protein promoter alters its expression but is not directly associated with atherosclerotic vascular calcification. Kobe Journal of Medical Sciences. 2004;50:69.

18. Abiri M, Sadeghian S, Hakki E, Boroumand M, Mehdipour P, Izadi $\mathrm{M}$, et al. T-138C and A-7G polymorphisms in the MGP gene and the association with coronary artery disease: Iranian patients. Tehran University Medical Journal. 2009; 67:94-100.

Copyright $\odot 2018$ The Author(s); Published by Society of Diabetic Nephropathy Prevention. This is an open-access article distributed under the terms of the Creative Commons Attribution License (http://creativecommons.org/licenses/by/4.0), which permits unrestricted use, distribution, and reproduction in any medium, provided the original work is properly cited. 